\title{
A Study of Association of Portal Vein Diameter And Splenic Size With Gastro-Oesophageal Varices in Liver Cirrhosis Patients
}

\author{
Dr. Ravi Shanker ${ }^{1}$,Dr. S.Banerjee (Professor Of Medicine) ${ }^{2}$,Dr. Anshul ${ }^{3}$,Dr. \\ Sujata Ganguly ${ }^{4}$, Dr. Saurav Bansal ${ }^{5}$, Dr. Abhimanyu Uppal ${ }^{6}$, Dr. Arun Singh \\ Bhadauriya $^{7}$,Dr. Shivang Patel ${ }^{8}$ \\ (Department Of Medicine, SMS Medical College , Jaipur )
}

\begin{abstract}
SMS Hospital, Jaipur were selected for the study. Ultrasonography was performed in all the cases and diameter of portal vein and spleen size was recorded. Endoscopy was performed in all the selected cases to look for oesophageal varices. Out of 50 patients $40(80 \%)$

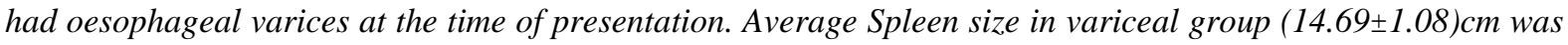
higher than in non-variceal group $(12.45 \pm 0.65) \mathrm{cm}, p<0.01$. The average portal vein diameter of patients in nonvariceal group was $11.78 \pm 1.58 \mathrm{~mm}$ and that of patients with varices $14.05 \pm 2.26 \mathrm{~mm}, p<0.01$. There was a positive correlation between spleen size and the Grades of oesophageal varices $(r=0.6771)$ and the difference was statistically significant $(p<0.01)$. There was a positive correlation between Portal vein Diameter and grades of oesophageal vaices $(r=0.7465), p<0.01$. In our study it was also found that there was a weak but definite correlation between Portal Vein Diameter and Spleen size $(r=0.5369)$ which was statistically significant $(p<0.01)$.

Hence from the present study it can be concluded that as the Grades of Varices increases the Spleen size and Portal Vein Diameter also increases.
\end{abstract}

\section{Introduction}

Chronic liver disease develops when the functional capacity of the liver can no longer maintain normal physiological conditions. Some forms of liver diseases are non progressive or only slowly progressive, other more severe forms are associated with scarring and architectural disorganization which if advanced, leads to cirrhosis. The scarring causes increased resistance to blood flow through the portal vein leading to ascites, oesophageal varices and increased morbidity and mortality.

Portal hypertension, a common complication of cirrhosis, results in the development of collateral to bypass the increased resistance to flow within the portal vein to return blood to systemic circulation ${ }^{1}$.

Gastrointestinal bleeding is the most sever complication of portal hypertension and oesophageal and gastric varices are by far the most common sources of bleeding in these patients. Variceal bleeding is one of the most dreaded complication of liver cirrhosis because of its attendant high mortality.

The prevalence of varices in patients with cirrhosis is approximately 50-60\% and risk of bleeding is $5 \%-15 \%$ with mortality rates of at least $20 \%$. Incidence of first variceal hemorrhage ranges from 20 to $30 \%$ within 2 years. Recurrent bleeding occurs in $30 \%$ to $40 \%$ of patients within the next 2 to 3 days and in up to $60 \%$ within 1 week ${ }^{2-5 .}$. Mortality is highest in the first 5 days after the index episode of variceal bleeding and returns to baseline by 3 to 4 months. This is the critical window for optimal treatment to improve the survival of variceal bleeders.

The rate of early re-bleeding translates into an increased rate of mortality. Therefore the presence of oesophageal varices is considered a prognostic indicator and a factor affecting the morbidity and mortality of surgical procedures. Despite the advantages of endoscopy, it is still an unpleasant and expensive invasive method. It also carries the risk of bleeding due to manipulation. Ultrasound findings in portal system (Portal vein diameter and spleen size) can predict both the presence of Varices and risk of Variceal bleeding. It can be used for diagnosis as well as long-term clinical monitoring of patients with portal hypertension. In view of the conflicting reports related to the non invasive predictors for the presence of oesophageal varices in some studies $^{6-7}$, it is worthwhile to study the correlation of portal vein diameter vis a vis spleen size and presence of gastro-oesophageal varices in liver cirrhosis patients.

\section{Material And Methods}

This is a Hospital based observational descriptive study. 50 patients with previously or newly diagnosed liver cirrhosis cases based on clinical, biochemical and ultrasonographic findings, attending S.M.S. Hospital, Jaipur were taken for this study. Patients having active gastro-intestinal bleed, past history of gastrointestinal bleed, on pharmacological treatment for portal hypertension, variceal ligation and sclerosant therapy, 
shunt surgery (TIPSS) and other causes of portal hypertension, i.e., non-cirrhotic portal fibrosis, Budd-Chiari syndrome, extrahepatic portal vein obstruction were excluded from the study.

\section{Clinical Examination}

Salient features in the history included occupation, alcohol intake, appetite, jaundice, fullness of abdomen, disorientation, unconsciousness, etc. A thorough general survey was done to assess pallor, cyanosis, jaundice, oedema engorged neck veins, palpable neck glands, pulse, and blood pressure. The gastrointestinal system was clinically examined with focus on the size of the spleen, liver span, presence of ascites, fluid thrill, palmer erythma, loss of axillary hair, presence of any venous prominence over the abdomen and gynaecomastia, testicular atrophy in men.

\section{Investigations}

Investigations like routine blood counts including platelet count, liver function tests (LFTs), Prothrombin Time(PT), INR, Routine urine analysis were obtained. Ultrasonography was performed in all cases and diameter of portal vein in $\mathrm{mm}$ and spleen size in $\mathrm{cm}$ was recorded. Upper gastrointestinal endoscopy was done to locate the varices.

Spleen size measurement: Spleen size was measured ultrasonographically by placing the patient in supine position, using 2-5 MHz curvilinear transducer in the coronal plane of section posteriorly in one of the lower left intercostal spaces. The average adult spleen measures $10-11 \mathrm{~cm}$ in length. A maximum cephalo-caudal measurement exceeding $13 \mathrm{~cm}$ indicates enlargement ${ }^{8}$.

Portal vein diameter measurement: In normal individuals, the portal vein diameter does not exceed $13 \mathrm{~mm}$ in quiet respiration, measured where the portal vein crosses anterior to the $\mathrm{IVC}^{9}$. This assessment is usually conducted with ultrasound views along the long axis of the portal vein. Diagnostic measurements were standardized by examining the patient in the supine position and in a state of quiet respiration.

Upper gastro-intestinal endoscopy : Endoscopy was performed in the department of gastroenterology, SMS Medical College and Hospital in all selected cases to look for gastro-oesophageal Varices and other associated signs of portal hypertension like red wale marks, cherry red spots.

\section{Grade of oesophageal varix description ${ }^{10}$}

Grade I - small varices without luminal prolapse;

Grade II - moderate-sized varices showing luminal prolapse with minimal obscuring of the gastro-oesophageal junction;

Grade III - large varices showing luminal prolapse substantially obscuring the gastro-oesophageal junction;

Grade IV - very large varices completely obscuring the gastro- oesophageal junction.

In patients with two different types of variceal grades, the higher variceal grade was considered for our study.

\section{Statistical Analysis}

Statistical analysis was done using computer software (SPSS version 20 and primer). The quantitative data were expressed in mean and standard deviation. Student ' $t$ ' test was used to infer the difference in means. Correlation analysis was done by using Pearson correlation coefficient and linear regression was performed. ROC curve analysis was used to find the best cutoff for sensitivity and specificity. The level of significance was kept $95 \%(\mathrm{p}<0.05)$ for all statistical analysis.

\section{Results}

A total of 50 patients with cirrhosis of liver were selected for the study, among them,38 were male (76\%) and remaining 12 were females (24\%). Patients were divided into two groups, those having varices grade $1-4$, were included in variceal group and those having no varices on endoscopy were put in Non-Variceal group. Out of 50 patients $40(80 \%)$ had oesophageal varices at the time of presentation. It was found that the prevalance of varices is almost equal in each age group.In our study it was found that incidence of chronic liver disease is more in males $38(76.0 \%)$ than female $12(24.0 \%)$. No sex difference in presence of oesophageal varices was present in chronic liver disease patients.In the present study it was found that alcoholic liver disease was more in males $(86.84 \%$ ) than females (no female case was found to be alcoholic). $28 \%$ of the total no. of patients were either Hepatitis B or Hepatitis C positive.

Average Platelet count was markedly lower in patients with varices $(97925 \pm 24361.0) / \mathrm{ml}$ than in patients without varices $(136800 \pm 50152.6) / \mathrm{ml}, \mathrm{p}<0.01$. Average S. Albumin was lower $(2.3 \pm 0.5) \mathrm{g} / \mathrm{dl}$ in patients with varices than in patients without varices $(3.2 \pm 0.4) \mathrm{g} / \mathrm{dl}, \mathrm{p}<0.01$. 
A Study Of Association Of Portal Vein Diameter And Splenic Size With Gastro-Oesophageal ....

\begin{tabular}{|l|l|l|l|}
\hline Parameter & $\begin{array}{c}\text { Variceal group } \\
(\mathbf{n = 4 0})\end{array}$ & $\begin{array}{c}\text { Non-variceal group } \\
(\mathbf{n}=\mathbf{1 0})\end{array}$ & P value \\
\hline Age(years) & $49.6 \pm 10.48$ & $51 \pm 15.38$ & $\mathrm{p}=0.7334$ \\
\hline Hemoglobin(g/dl) & $10.3 \pm 1.2$ & $10.9 \pm 1.1$ & $\mathrm{p}=0.1718$ \\
\hline T.Bil(mg/dl) & $5.1 \pm 2.4$ & $5.9 \pm 2.8$ & $\mathrm{p}=0.3694$ \\
\hline Platelete count/ml & $97925 \pm 24361$ & $136800 \pm 50152.6$ & $<0.01$ \\
\hline TLC(X 10^3/dl) & $8.3 \pm 3.3$ & $8.6 \pm 3.8$ & 0.7979 \\
\hline S. albumin(g/dl) & $2.3 \pm 0.5$ & $3.2 \pm 0.4$ & $<0.01$ \\
\hline INR & $1.80 \pm 0.434$ & $1.63 \pm 0.206$ & 0.2369 \\
\hline Spleen Size $(\mathbf{c m})$ & $14.69 \pm 1.08$ & $12.45 \pm 0.65$ & $<0.01$ \\
\hline PV diameter(mm) & $14.05 \pm 2.26$ & $11.78 \pm 1.58$ & $<0.01$ \\
\hline
\end{tabular}

Average spleen size in variceal group $(14.69 \pm 1.08) \mathrm{cm}$ is higher than in non variceal group $(12.45 \pm 0.65) \mathrm{cm}, \mathrm{p}<0.01$. There was $90 \%$ sensitivity and $80 \%$ spesificity for prediction for presence of oesophageal varices when the cutoff value( by ROC curve analysis) of spleen size for was $>13.5 \mathrm{~cm}$. also there was a positive co-relation between spleen size and grades of oesophageal varices $(\mathrm{r}=0.6771), \mathrm{p}<0.01$.

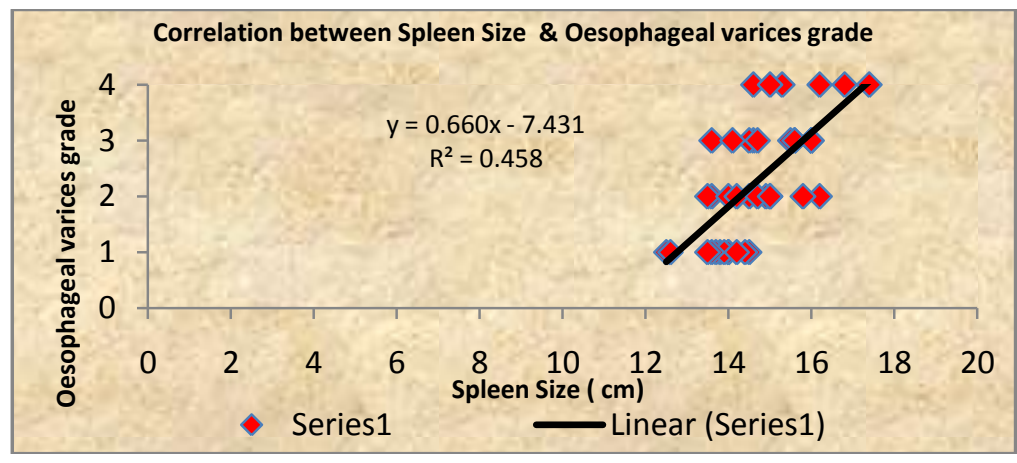

The average portal vein diameter of patients in non-variceal group was $11.78 \pm 1.58 \mathrm{~mm}$ and of patients with varices $14.05 \pm 2.26 \mathrm{~mm}, \mathrm{p}<0.01$.It was also found that there is a correlation between Portal Vein Diameter and the Grades of oesophageal varices ( $\mathrm{r}=0.7465)$, also the best cutoff of Portal Vein Diameter for prediction of oesophageal varices is $>12.2 \mathrm{~mm}$ (Sensitivity $=80 \%$, Specificity $=80 \%$ ).

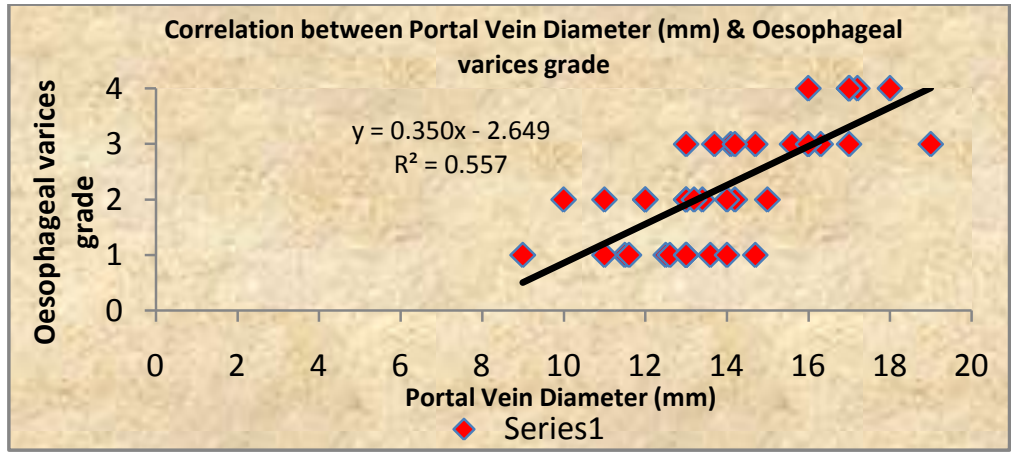

There was also a weak but definite co-relation between spleen size and Portal Vein Diameter $(\mathrm{r}=0.5369)$ in patients with chronic liver disease which is highly significant $(\mathrm{p}<0.01)$.

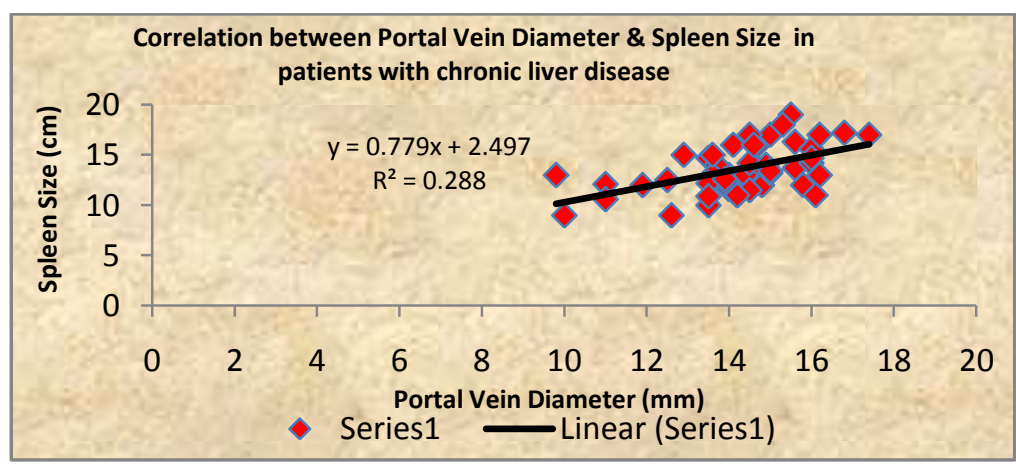




\section{Discussion}

Present study was done with the aim to predict the presence of oesophageal varices in patients with chronic liver disease, correlation between portal vein diameter and splenic size with gastro -oesophageal varices and to know the correlation between spleen size and portal vein diameter in patients with chronic liver disease. This study was compared with different studies done by different authors.

Incidence of chronic liver disease was almost equal in each age group, total number of male patients being $76 \%$ and female patients being $24 \%$ in our study. This findings is comparable with the study by Gianini et $\mathrm{al}^{11}$ in which male and female incidence was $71 \%$ and $29 \%$ respectively.

We observed that the incidence of oesophageal varices is almost equal in every age group meaning age is not a causative factor for development of varices and can happen at any age which is supported by the study of Madhotra $\mathrm{R}^{12}$.

There was no significant difference in the TLC in variceal or non- variceal group which is supported by study of Sharma et. al. ${ }^{13}$ but refuted by Gue et. al. ${ }^{14}$. This contradiction with our study can be explained by the fact that TLC depends on various factors like ongoing infective process, spleen size, and deficiency of various nutritional factors.

We report that platelet count of $<120,000 / \mathrm{mm}$ is $90 \%$ sensitive and $50 \%$ specific predictor of oesophageal varices with positive predictive value of $87.8 \%$ and negative predictive value of $55.56 \%$. Other studies done by Pilette et al. ${ }^{15}$ (116 patients) and Thomopoulos et al. ${ }^{16}$ (184 patients) found that platelet count $<118000$ was good predictor for presence of varices with sensitivity $95 \%$, specificity $73 \%$ and reported a low platelet count to be an independent risk factor for the presence of varices.

We observed that average S. Albumin was lower $(2.3 \pm 0.5) \mathrm{gm} / \mathrm{dl}$ in patients with varices than in patients without varices $(3.2 \pm 0.4) \mathrm{gm} / \mathrm{dl}, \mathrm{p}<0.01$ Studies by Bresseler et. al. ${ }^{17}$ and Sarwar et al. ${ }^{6}$ also found that low S. albumin was independently associated with presence of oesophageal varices, however another study by Cherian et al. ${ }^{18}$ and Rye K et al. ${ }^{19}$ found the correlation between Albumin and oesophageal varices insignificant. This contradiction could be explained by variation among studies regarding etiology, stage of liver cirrhosis and the duration of illness.

The average spleen size was higher in variceal group than non variceal group $(14.69 \pm 1.08) \mathrm{cm}$ vs $(12.45 \pm 0.65) \mathrm{cm} \mathrm{p}<0.01$. When cutoff of spleen size was taken as $>13.5 \mathrm{~cm}$ for prediction of oesophageal varices the sensitivity and specificity were $90 \%$ and $80 \%$ respectively which is the best cutoff of Spleen size. These findings are supported by the woks of Chalasani et al. ${ }^{20}$ who found spleen size as an independent factor determining risk of varices. Splenic size of $>131.5 \mathrm{~mm}$ and $>131.29 \mathrm{~mm}$ were associated with presence of oesophageal varices in cirrhosis as studied by Serag Esmat et $\mathrm{al}^{21}$ and Lopamudra Mandal et al. ${ }^{22}$ respectively.

The average Portal Vein diameter in variceal group $(14.05 \pm 2.26) \mathrm{mm}$ is significantly higher than in Non-variceal group $(11.78 \pm 1.58) \mathrm{mm}$. To predict the presence of oesophageal varices when cutoff of Portal Vein Diameter was taken as $>12.2 \mathrm{~mm}$ the sensitivity and Specificity, were $80 \%$ and $80 \%$, respectively which is the best cutoff point. Sudhindra D. Lakshman Kumar et al. ${ }^{23}$ and Schepis et al. ${ }^{24}$ found in their study that portal vein diameter $>13 \mathrm{~mm}$ is an independent non invasive predictors of varices.

There is a positive correlation between spleen size and the Grade of oesophageal varices ( $r=0.6771), p$ $<0.01$ i.e. as the Spleen Size increases the grade of varices increases which is supported by studies done by Lopamudra et al. ${ }^{22}$ on 82 patients $(r=0.467 ; \mathrm{p}<0.001)$, and Nemichandra et al. ${ }^{25}$.

There was a positive correlation between Portal Vein Diameter and the Grade of oesophageal varices $(\mathrm{r}=0.7465), \mathrm{p}<0.01)$. i.e. as the Portal Vein diameter increases the Grade of oesophageal Varices increases.These findings were supported by the works of Lopamudra et $\mathrm{al}^{22}{ }^{22}$,Nemichandra et al ${ }^{25}$ and KV Sudha Rani et al. ${ }^{26}$

We found that there is a weak but definite correlation between the Portal vein Diameter and Spleen Size i.e as the Portal Vein Diameter increases the spleen size increases in patients with chronic liver disease $(\mathrm{r}=0.5369)$ which is statistically significant $(\mathrm{p}<0.01)$. This is because that there is a linear increase in both parameters with increasing Portal Hypertention.

\section{Conclusion}

In patients with liver cirrhosis with no past history of gastro oesophageal bleeding

- Platelet count and Serum albumin can be a predictor for the presence of gastro-oesophageal varices.

- As the grade of varices increases the spleen size also increases.

- As the grade of varices increases the portal vein diameter also increases

- As the Portal Vein Diameter increases the spleen size increases in patients with chronic liver disease $(\mathrm{r}=0.5369, \mathrm{p}<0.01)$. 


\section{Bibliography}

[1]. De Franchis R, Primignani M. Natural history of portal hypertension in patients with cirrhosis. Clinics in liver disease. 2001 Aug 1;5(3):645-63.

[2]. D'Amico G, Garcia-Tsao G, Pagliaro L. Natural history and prognostic indicators of survival in cirrhosis: a systematic review of 118 studies. J Hepatol. 2006;44:217-231

[3]. D’Amico G, De Franchis R. Upper digestive bleeding in cirrhosis. Post-therapeutic outcome and prognostic indicators. Hepatology. 2003;38:599-612.

[4]. Rigo GP, Merighi A, Chalen JN, et al. A prospective study of the ability of three endoscopic classifications to predict hemorrhage from esophageal varices. Gastrointest Endosc $1992 ; 38: 425-9$.

[5]. Jensen DM. Endoscopic screening for varices in cirrhosis : findings, implications and outcomes. Gastroenterology 2002 ; 122 :1620-30.

[6]. Sarwar S, Khan AA, Alam A et al. Non-endoscopic prediction of presence of oesophageal varices in cirrhosis. J Coll Physicians Surg Pak 2005; 15 (9): 528-31

[7]. Dib N, Konate A, Obesti F, Cales P. Non-invasive diagnosis of portal hypertension in cirrhosis. Application to the primary prevention of varices. Gastroenterol Clin Biol 2005; 29 (10): 975-87

[8]. Senecail B. Sonographic Anatomy of the Normal Spleen, Normal Anatomic Variants, and Pitfalls. In Ultrasonography of the Spleen 1988 Jan 1 (pp. 1-13). Springer Berlin Heidelberg

[9]. Goyal AK, Pokharna DS, Sharma SK. Ultrasonic measurements of portal vasculature in diagnosis of portal hypertension. A controversial subject reviewed. J Ultrasound Med 1990; 9: 45-8

[10]. Paqet KJ. Prophylactic endoscopic sclerosing treatment of the oesophageal wall in varices: A prospective controlled trial. Endoscopy 1982; 14: 4.

[11]. Giannini E, Botta F, Borro P, et al. Platelet count/spleen diameter ratio: proposal and validation of a non-invasive parameter to predict the presence of oesophageal varices in patients with liver cirrhosis. Gut. 2003;52(8):1200-1205

[12]. Madhotra R, Mulcahy HE, Willner I, et al. Prediction of esophageal varices in patients with cirrhosis. J Clin Gastroenterol 2002 ; 34 : 81-5.

[13]. Sharma SK, Aggarwal R. Prediction of large oesophageal varices in patients with cirrhosis of the liver using clinical, laboratory and imaging parameters. Journal of Gastroenterology and Hepatology 22 (11): 1909-15, November 2.

[14]. Gue, C. S., C. K. Yap, and H. S. Ng. "The correlation between cytopenia and esophageal varices in patients with liver cirrhosis." Med J Malaysia 59.5 (2004): 605.

[15]. Pilette C, Oberti F, Aube C: Non-invasive diagnosis of esophageal varices in chronic liver disease. J Hepatol 1999;31:867-73.

[16]. Thomopoulos KC, Labropoulou-Karatza C, Mimidis KP, Katsakoulis EC, Iconomou G, Nikolopoulou VN. Non-invasive predictors of the presence of large oesophageal varices in patients with cirrhosis. Dig Liver Dis. 2003 Jul;35(7):473-8

[17]. Bressler B. Which patients with primary biliary cirrhosis or primary sclerosing cholangitis should undergo endoscopic screening for oesophageal varices detection?. Gut. 2005;54(3):407-410.

[18]. Cherian JV, Deepak N, Ponnusamy RP, Somasundaram A, Jayanthi V. Non-invasive predictors of esophageal varices. Saudi J Gastroenterol. 2011 Jan-Feb;17(1)

[19]. Rye K, Scott R, Mortimore G, Lawson A, Austin A, Freeman J. Towards Noninvasive Detection of Oesophageal Varices. International Journal of Hepatology. 2012;2012:1-9.

[20]. Chalasni N, Imperiale TF, Ismail A, et al. Predictors of large esophageal varices in patients with cirrhosis. Am J Gastroenterol 1999 ; $94: 3285-91$

[21]. Serag Esmat and Dalia Omran. Study of noninvasive predictors of portal hypertension in liver cirrhotic Egyptian patients. Journal of American Science 2011

[22]. Lopamudra Mandal, Sanjay Kumar Mandal, Dipanjan Bandyopadhyay, Saumik Datta. Correlation of portal vein diameter and splenic size with gastro-oesophageal varices in cirrhosis of liver. JIACM 2011

[23]. Sudhindta D Lakshman Kumar et al JAPI Vol. 5 December 2003

[24]. Schepis, F., Cammà, C., Niceforo, D., Magnano, A., Pallio, S., Cinquegrani, M., D'Amico, G., Pasta, L., Craxì, A., Saitta, A. and Raimondo, G. (2001), Which patients with cirrhosis should undergo endoscopic screening for esophageal varices detection?. Hepatology, 33: 333-338.

[25]. Nemichandra,Kenny Singh Salam, Vilas Yadavarao Kanse, Nisar Shiakh, Dhanaraj Singh, Kulachandra Singh Non Endoscopic Predictors of Esophageal Varices in Patients with Cirrhosis of Liver IOSR Journal of Dental and Medical Sciences (IOSR-JDMS).Volume 14, Issue 1 Ver. II (Jan. 2015), PP 65-68

[26]. Rani KS, Sudarsi B, Siddeswari R, Manohar S. Correlation of Portal Vein Size with Esophageal Varices Severity in Patients with Cirrhosis of Liver with Portal Hypertension 